\title{
Knowledge management as a platform for the strengthening of intellectual capital in private universities
}

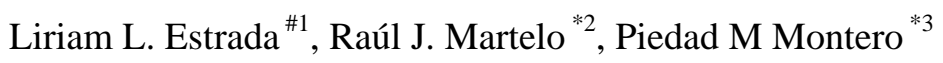 \\ \# Rafael Belloso Chacín University \\ ${ }^{1}$ lestrada@urbe.edu.co. \\ * Faculty of Engineering \\ University of Cartagena, Cartagena, Bolívar, Colombia. \\ 2 rmartelog1@unicartagena.edu.co \\ 33pmargaritamontero@unicartagena.edu.co
}

\begin{abstract}
In this research, knowledge management was analyzed as a platform for the strengthening of intellectual capital in private universities in the municipality of Maracaibo. The methodology implemented in this study was of a descriptive correlational type and with a non-experimental, crosssectional, descriptive and field design. The data analysis was through descriptive statistics, in which the population was made up of teachers from private universities: Jose Gregorio Hernandez, Rafael Urdaneta and Rafael Bellozo Chacín, and the sample was constituted by 30 teachers (10 from each institution). The results point, among other things, to the need to strengthen the knowledge phases (creation, capture and acquisition, development and dissemination) through the implementation of strategies and policies, aimed at managing knowledge in teachers and interns.
\end{abstract}

Keyword - Skills, Competencies, Creativity, Knowledge, Managerial approaches, Organizational management

\section{INTRODUCTION}

Knowledge is perceived as an intangible asset [1] and difficult to assess [2]. For this reason, it is essential that organizations maintain talent through the administration of human resources [3]. Consequently, management of organizational knowledge is presented as a tool to acquire sustainable competitive advantages in a company [4]. Taking into account the description, this becomes a topic of interest for educational institutions, because it supports the review of organizational strategies used to improve aspects that intervene in the increase of knowledge-based activities with respect to the objectives established by the institution [5]. Therefore, it is important to understand the organizational approach to knowledge management in higher education institutions (HEIs) [6]. It is significant as a strategy to achieve synergies among the members of a university community; in order to achieve a better and higher level of production in terms of the inherent functions of teaching, research and extension. On the basis of the ideas presented can be cited Universities that make previous efforts to measure intellectual capital.

According to [7], with the organization of Austrian universities, the Ministry of Science and Culture decided to study the potential to report intellectual capital for universities in 2001. The intellectual capital report model for universities tries to visualize the process of knowledge production and consists of four elements: goals, intellectual capital, performance processes and impacts. The model approach can be categorized as process oriented. Three elements of intellectual capital are identified: human, structural and relational capital. Similarly, in the National University of Colombia with the application of existing models, evidence a contrast in the components of human capital (learning and growth), Structural Capital (internal processes), Relational Capital (customers), to solve and identify internal problems of the institution to respond satisfactorily to the selfassessment processes of the National Accreditation System, as governmental entities to guarantee society compliance with quality criteria, to achieve purposes and objectives.

Other authors such as [8], proposed a model for the support of teaching and learning activities in higher education, by studying the components related to social networks and knowledge management. In addition, [9] designed a framework where there were implemented the concepts of management of the knowledge, for the development of the creative thought in the higher education, together with the learning based on projects. [10] show information related to knowledge management, which serves as references to achieve success in the operation of public universities. Another related study is carried out by [11], who defined the performance of the Al-Azhar University and the Al-Quds Open University in the Gaza Strip, Palestine, through the evaluation of maturity of knowledge management. In [12], the integration of e-learning with knowledge management is studied through the characteristics of the current system, the models and management requirements. 
Taking into account the studies and results presented, it is evident that the difficulties in the different HEIs for the implementation of the knowledge management, lies not only in the lack of economic or technological resources, also with the less institutional support, the less incentive to the research that raises the quality of the teachers that make up the panorama that surrounds the universities, therefore lacks stimulus to the management of intellectual capital. For this reason, this research aims to design guidelines for knowledge management as a platform for intellectual capital in private universities: Rafael Belloso Chacín University, Cecilio Acosta University and José Gregorio Hernández University of Maracaibo Municipality.

\section{MATERIALS AND METHODS}

This research is framed under a quantitative approach, in that regard [13] describes the research as quantitative when measuring the amplitude of the variables, statistical data is determined and generalized, in addition it is used for the construction of support for a hypothesis or theory.

On the other hand, a non-experimental design was adopted because the manipulation of the independent variables was not carried out, that is, only the description of a particular situation was provided without intervening [14]. Therefore, the instrument was applied in the teaching, research and extension areas of the private universities of the Maracaibo Municipality. For the development of the research, the next steps described were stipulated (Figure 1):

A)

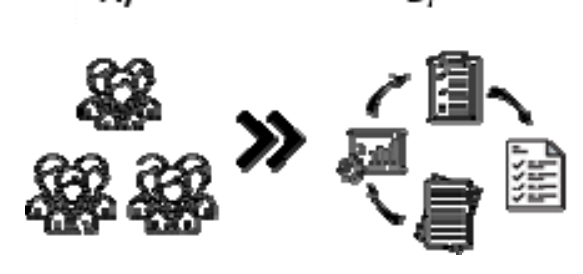

Fig. 1: Scheme proposed for the development of research.
D)

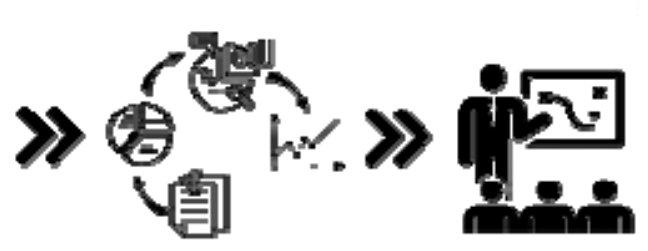

A) Identification and selection of Population and Sample: The study population consisted of professors of private universities internships José Gregorio Hernández, Rafael Urdaneta and Rafael Belloso Chacin University, which have a number of 10 teachers each. With respect to the sample, a non-probabilistic sampling was carried out. With respect to the sample, a non-probabilistic sampling was carried out. For the sample, the selection criteria were taken: more than one (1) year of service, experiences of more than (5) years of services and academic degree with mastery. In Table 1, the sample is indicated according to the mentioned criteria.

TABLE 1. Sample characteristics

\begin{tabular}{|c|c|}
\hline Private universities & Teachers \\
\hline José Gregorio Hernández & 10 \\
\hline Rafael Urdaneta & 10 \\
\hline Rafael Belloso Chacín & 10 \\
\hline Total & 30 \\
\hline
\end{tabular}

B) Construction validity and reliability of the information collection instrument: For the purposes of this research, a questionnaire was applied, which consisted of 60 items, whose response options are always, almost always, sometimes, almost never, never. This type of scale avoids the bias of the answers provided, in order to specify the behavior of the Knowledge Management and Intellectual Capital variables.

The logical review of the instrument was carried out by a group of ten people, who were considered experts in the academic field in the areas of Knowledge Management and Intellectual Capital as well as research methodology. This technique, guarantees that the questions or items are consistent with the objectives, dimensions and indicators that are intended to measure in the research object of study.

The validity instruments were subjected to the judgment of ten experts in both variables, in turn a pilot test was applied to a sample, with characteristics similar to the population under study, to have reliability using the Cronbach's Alpha Coefficient, whose formula is the next:

$$
r_{t t}=\frac{K}{K-1}\left(1-\frac{\sum S_{i}^{2}}{S_{t}^{2}}\right)
$$


Wherein:

$\mathrm{K}=$ Number of items that the instrument has

$\mathrm{r}_{\mathrm{tt}}=$ Reliability coefficient

$\mathrm{S}_{\mathrm{i}}{ }^{2}=$ Variance of the scores of each item

$\mathrm{S}_{\mathrm{t}}^{2}=$ Variance of totals

Reliability ranges were established to categorize the result obtained in Cronbach's Alpha coefficient, as shown in Table 2.

TABLE 2. Reliability scale

\begin{tabular}{|c|c|}
\hline Range & Magnitude \\
\hline 0.81 a 1.00 & Very High \\
\hline 0.61 a 0.80 & High \\
\hline 0.41 a 0.60 & Moderate \\
\hline 0.21 a 0.40 & Low \\
\hline 0.01 a 0.20 & Very Low \\
\hline
\end{tabular}

C) Analysis of the results of the research: In the statistical analysis of the questionnaires, the SPSS program is used. In addition, in order to obtain the results and in its subsequent analysis, the Variance Analysis (ANOVA) technique was applied, which compares the measurements of the data obtained from the surveyed population. In Table 3, the scale for the interpretation of the data is shown.

TABLE 3. Scale for Interpretation of Data

\begin{tabular}{|c|c|c|c|}
\hline Range & score & Answers & Analysis Categories \\
\hline $4.21-5.00$ & 5 & Always & Very High \\
\hline $3.41-4.20$ & 4 & Usually & High \\
\hline $2.61-3.40$ & 3 & Sometimes & Moderate \\
\hline $1.81-2.60$ & 2 & Rarely & Low \\
\hline $1-1.80$ & 1 & Never & Very Low \\
\hline
\end{tabular}

D) Conclusions, recommendations and guidelines: In this step the conclusions were determined, and recommendations and guidelines were made according to the results.

\section{III.RESULTS}

The results obtained in the development of the investigation are shown below.

A. Analysis of the research results

The data obtained from the collection instrument were tabulated according to the questions and assets to continue with the analysis of the results obtained for each item and its discussion according to the dimensions and indicators of the study variables.

According to the research objective, variables, dimensions, indicators and sub-dimensions were determined (Table 4)

TABLE 4. Study variables, dimensions, indicators y sub-dimensions

\begin{tabular}{|c|c|c|c|}
\hline Variables & Dimensions & Sub-dimension & \# Indicators \\
\hline $\begin{array}{l}\text { Knowledge } \\
\text { management }\end{array}$ & Knowledge Phases & & 4 \\
\hline \multirow[t]{4}{*}{$\begin{array}{c}\text { Intellectual } \\
\text { Capital }\end{array}$} & Transfer mechanism & & 2 \\
\hline & \multirow{3}{*}{ Components of intellectual capital } & Human capital & \multirow{3}{*}{10} \\
\hline & & Structural Capital & \\
\hline & & Relational Capital & \\
\hline
\end{tabular}

\section{i. Dimension: Knowledge phases}

The results obtained for the indicators of the "Knowledge Phases" dimension is shown below, which had a significance level of 0.349 , this value being greater than 0.05 ( $0.349>0.05$, level of referential significance). Taking into account the above, there are highly significant differences among the compared indicators, therefore, not all have the same degree of presence within this dimension (Table 5). 
TABLE 5. Dimension: Knowledge Phases

\begin{tabular}{|l|l|l|l|l|l|}
\hline ANOVA \\
\hline Source & Sum of squares & Degrees of freedom & Root mean square & F & Sig. \\
\hline Inter-groups & 0.837 & 3 & .279 & 1.107 & .349 \\
\hline Intra- groups & 29.240 & 116 & .252 & & \\
\hline Total & 30.076 & 119 & & & \\
\hline
\end{tabular}

The comparison of the Tukey's ranges multiples test reveals the differences among the various indicators of the dimension "Knowledge Phases" of the Knowledge Management variable. At the same time, the variation in error between the variance of the indicators was highlighted (Table 6).

TABLE 6. Dimension: Knowledge Phases, ANOVA of a factor, homogeneous subsets

\begin{tabular}{|l|l|l|}
\hline \multirow{2}{*}{ Factor 1} & \multirow{2}{*}{$\mathrm{N}$} & Subset for alpha $=0.05$ \\
\cline { 3 - 3 } & & 1 \\
\hline Diffusion & 30 & 2.8225 \\
\hline Development & 30 & 4.1223 \\
\hline Capture & 30 & 4.2000 \\
\hline Creation & 30 & 4.2003 \\
\hline Sig. & & .349 \\
\hline
\end{tabular}

In Table 6, the results of the established comparison are exposed, where the multiple range test of Tukey placed them in a set based on the similarity and differences in behavior between their means. A significant difference is observed with the diffusion indicator, because the answers issued by the respondents allow locating the level of importance of the indicators through statistical treatment in Table 6. Likewise, it is revealed that the "Diffusion" indicator is the first at the level of importance in Knowledge Management, which allows characterizing the "Knowledge phases ", followed by the indicator "Development", then the indicator "Capture" and by last one corresponding to the "Creation" indicator.

The averages of the indicators: Development, Capture and Creation were placed in the high category, according to the established interval, therefore, the knowledge generated within the area of the internships was recorded and stored. However, the Diffusion indicator was placed in the "Moderate" category, according to the established interval. These results show similarities among the criteria expressed by the reporting subjects, except for the Diffusion that is moderate. Some informants stated that knowledge exchange is sometimes promoted, and strategies are formulated for the dissemination of knowledge with the environment, in the same way that knowledge is monitored.

According to what has been described, the results do not coincide with what was proposed by [6], in terms of the order of importance in the process, because the results showed an order of importance in the Development of knowledge as well as the other indicators, with the exception of the Diffusion indicator. According to [15], business management is a complex process in the environment that is currently presented, where opportunities must be identified from abroad and growth must be sought. For this reason, organizations must be agile, capable and oriented towards the development of learning and organizational knowledge capacities. It should be noted that the development of knowledge is an indicator of relevance for the knowledge phases in any organization, coinciding with the informants in that it is a system that learns to the extent that it perceives the transformations of the environment.

On the other side, [16] defines the acquisition of knowledge as the process by which organizations appropriate missing information from the external environment. This process is linked to the identification of knowledge, because it provides information about the intangible asset that is not in the organization, besides, it is necessary to develop clear information that nurtures the management of it.

Likewise, the indicator referred to the creation or acquisition of knowledge is necessary to determine its management, as part of the information gathering process to carry out a knowledge management initiative, because once it is identified, it grows and can be manipulated, which is why organizations must have a continuous knowledge renewal.

To achieve a knowledge management process, it is necessary that dissemination strategies exist. In consequence, they must be in accordance with the objectives established by the organization, taking into account that the indicator corresponding to the Diffusion is relevant according to the result obtained.

According to [17], promoting the dissemination of knowledge of science supports its development and avoids the redundancy of efforts, in order to increase the research of new knowledge. In this sense, programs for the dissemination of science should be systematically established, spaces for academic exchange and culture that are 
carried out by the different entities of the university community should be increased. Therefore, the respondents affirm that it is necessary the exchanges, strategies and the monitoring of the diffusion of knowledge in the Universities.

\section{ii. Dimension: Transfer Mechanisms}

In the indicators of the dimension Transfer Mechanisms, a level of significance of 0.590 was obtained, the value being greater than 0.05 ( $0.590>0.05$ level of referential significance); it is revealed that there is a highly significant difference among the compared indicators, with this it is pointed out that not everyone has the same degree of presence within this dimension. Next, in Table 7, the behavior of the subjects in the investigated context is presented.

TABLE 7. Dimension: Transfer mechanisms

\begin{tabular}{|c|c|c|c|c|c|}
\hline Source & $\begin{array}{c}\text { Sum of } \\
\text { squares }\end{array}$ & $\begin{array}{c}\text { Degrees of } \\
\text { freedom }\end{array}$ & $\begin{array}{c}\text { Root mean } \\
\text { square }\end{array}$ & $\mathrm{F}$ & Sig. \\
\hline Inter-groups & .625 & 3 & 2.38 & .666 & .590 \\
\hline Intra- groups & 36.300 & 116 & 2.55 & & \\
\hline Total & 36.925 & 119 & & & \\
\hline
\end{tabular}

In the same way, the comparison of Tukey's multiple range test reveals the difference between the indicators of the "Transfer Mechanisms" dimension corresponding to the variable "Knowledge Management". Likewise, the error variation between the variance and the indicators is highlighted (Table 8).

TABLE 8. Dimension: Transfer mechanisms

\begin{tabular}{|c|c|c|c|c|}
\hline Factor 2 & $\mathrm{N}$ & Root mean square & Standard deviation & $\mathrm{S}$ \\
\hline Institutional relations & 30 & 2.388 & 0.59672 & 0.59 \\
\hline Knowledge networks & 30 & 2.554 & 0.70652 & 0.706 \\
\hline
\end{tabular}

In Table 8, the results of established comparisons are presented, where Tukey's multiple range test have located a set located in the same behavior similarity between its means. On the other hand, the Institutional Relations indicator is presented with a moderate score, with an average of 2.388. In the same set, the Knowledge Networks indicator was positioned with a moderate average of 2.554 . According to the analysis, there is low significant difference among these indicators. It should be noted that the Knowledge Networks indicator is based on the preference of the respondents, which indicates that this indicator deserves consideration for the Transfer Mechanisms of the private universities studied. In the same way, it is important to point out that in the private University Institutions they assign importance to the Knowledge Networks, such as (telephone, email) to share knowledge.

The average of the Institutional Relations indicator was placed in the "Low" analysis category, in the interval $(1.80<2.60)$, where the informants affirmed that cooperation agreements with other institutions of the state are sometimes promoted in the university. Likewise, the transfer mechanisms are favored for the inter-institutional benefit and a transfer process is applied that optimizes the movement of knowledge of the university. Taking into account the above, the Knowledge Networks were placed in the low analysis category in the established interval $(1.80<2.60)$, according to these results, networks are sometimes established (telephone, email) to share knowledge, connections with other institutions are promoted for knowledge exchange and there is not a network that contains the different knowledge sectors, these results of trends reveal low contradiction in the criteria manifested by the subjects informants, who agree that the indicators are in the "Low" category, respectively.

According to the results, academic and institutional cooperation should be established internally and externally in order to carry out joint projects, learn from others, join efforts to achieve new objectives and unite efforts to achieve the objectives set. Regarding the indicator "Knowledge Networks", for [18] knowledge networks are groups of people and their knowledge links that interact and exchange outstanding information.

\section{iii. Dimension: Intellectual Capital}

In regard to the study of the variable "Intellectual Capital", the general results show the behavior assumed by the subjects around the research carried out. It should be noted that this section is aimed at determining the components of intellectual capital, using the Intellectus model in private universities. When applying the statistical technique Analysis of variance (ANOVA), the significance reached by the sub-dimensions corresponding to the dimension "Components of Intellectual Capital" is specified. According to the above, a significance level of 0.034 was obtained, this value being less than $0.05(0.034<0.05$, level of referential significance). Consequently, it is shown that there are highly significant differences among the compared indicators, which indicates a difference of significance in the corresponding dimension, then the behavior of the subjects in the investigated contexts is shown (Table 9). 
TABLE 9. Dimension: Intellectual Capital Components

\begin{tabular}{|l|l|l|l|l|l|}
\hline Source & Sum of squares & Degrees of freedom & Root mean square & F & Sig. \\
\hline Inter-groups & 4.024 & 3 & 1.341 & 2.998 & 0.034 \\
\hline Intra- groups & 51.898 & 116 & 0.447 & & \\
\hline Total & 55.922 & 119 & & & \\
\hline
\end{tabular}

Next, the comparison of the Post Hoc Tukey multiple range test is shown, which reveals the difference between the indicators of the sub-dimensions: Human Capital, Structural Capital and Relational Capital, which correspond to the dimension "Components of Human Capital" of the Intellectual Capital variable, likewise highlights the variation of the errors in the variances between the indicators (Table 10).

TABLE 10. Dimension: Intellectual Capital Components, ANOVA of a factor, homogeneous subsets

\begin{tabular}{|c|c|c|c|}
\hline \multirow{2}{*}{ Factor 3 } & \multirow{N}{*}{$\mathrm{N}$} & \multicolumn{2}{|c|}{ Subset of alpha $=0.05$} \\
\cline { 3 - 4 } & & 1 & 2 \\
\hline Structural & 30 & 3.7337 & \\
\hline Relational & 30 & 3.9667 & 3.9667 \\
\hline Social & 30 & 4.1120 & 4.1120 \\
\hline Human & 30 & & 4.2000 \\
\hline Sig. & & .132 & .449 \\
\hline
\end{tabular}

In Table 10, the results of the established comparison are presented, where the Tukey's multiple test, have located two subsets established in the similarity and differences in behavior between the means. According to the results, the sub-dimension "Structural" obtained the lowest score, with an average of 3.7337 points. In the same sub-set the "Relational" was located with an average of 3.9667 points. In the second subset the subdimension "Human" was placed with the highest value of 4.2000 points. Through the analysis carried out, it was possible to observe the significant differences among the sub-dimensions, as well as among the groups. From the above, the opinion expressed by the population under study is considered, through which two subsets were established, revealing moderately significant differences among the sub-dimensions: Structural and Relational, with respect to the sub-dimension "Human". Therefore, the results are specified more precisely by studying the sub-dimensions of the Intellectual Capital Component. The results obtained from the sub-dimension Human in Table 10 follow the affirmation of the subjects surveyed at the time of issuing their response, which indicates that the human component represents the first aspect that deserves to be considered with greater degree of importance within the components of human capital in institutions of Private University Education.

It is important to clarify that in the results of Table 10, the Social component appears, but it was not taken into account to determine the components of the Intellectus model, which can be incorporated into the processes that are fulfilled in the university organizations under study. In regard to Capital, this plays an important role in organizations, because it is the knowledge that the individual possesses within the organization and although it is considered the most precious asset that an organization has, not all of them implement actions tending to strengthen, develop and enhance this asset, which gives the organization added value.

The averages for the sub-dimensions: Structural and Relational Capital, were placed in the analysis category "High" in the established interval $(3.41<4.20)$. According to the results, the informants agreed that the acquisition of new competencies is encouraged through organizational learning, as well as the existence of a salary reward system when carrying out some research activity. In the same way, they have a data bank according to the requirements of the organization and develop projects in the social area that support community organizations. It also has established links with other universities in the country and abroad, while the subdimension "Human Capital" was "High" in the interval $(4.20<5.0)$. The respondents affirmed that the flexibility is assumed to make possible the changes derived from the needs of the university organization and executing actions aimed at developing human talent in the execution of work, stimulating in human talent the social skills to work in multidisciplinary teams. These results reflect little emphasized contradictions among the criteria expressed by the informants, considering that the components of Human Capital are high and very high respectively.

According to the results obtained, the Structural component can be considered when establishing a classification of the elements that make up Intellectual Capital. In addition, the contributions made by authors are considered, for example, [19] establish that in intellectual capital organizations deals with intangible assets related to knowledge, used in the production process and that generate gains in the market. It can be divided into Human Capital and Structural Capital. The separation between the intellectual capital "thinking" and the "nonthinking" can be considered as the criterion of differentiation at this level. The reason is that people and, 
therefore, human capital, need management methods completely different from structural capital, which is supported by the informants surveyed and whose result was divided into two (2) different subgroups.

According to the Intellectus model proposal in [20], structural capital is made up of organizational and technological capital, which represents the organization's own knowledge and arises to the extent that it is owned by the entity's people and teams, even if it is explicit, codified, systematized and internalized by the organization, through a formal process of creation of a successive series of organizational routines or guidelines of action, which are systematized and socialized by the organization.

Regarding the indicator Relational capital, respondents affirm that links should be established with other universities in the country or abroad, create research projects whose results will be applied to specific situations of the same and develop projects in the social area that support community organizations.

\section{i. Sub-dimension: Human Capital}

To determine the components of Intellectual Capital, the statistical technique, Analysis of Variance (ANOVA), was used, which determined the significance reached by the indicators of the sub-dimensions, starting with the indicators of the sub-dimension Human Capital, which it consists of three indicators: Values, Aptitudes and Capacities. Then, through the application of statistical analysis (ANOVA), it was possible to analyze the variance and the significance obtained for the indicators of the sub-dimension "Human Capital" was determined, which had a level of significance of 0.349 , value greater than $0.05(0.349>0.05$, level of referential significance). Taking into account the above, there are highly significant differences among the compared indicators, so that all do not have the same degree of presence within this dimension, as shown in Table 11.

TABLE 11. Level of Significance, Sub-Dimension Human Capital

\begin{tabular}{|c|c|c|c|c|c|}
\hline & Sum of squares & Degrees of freedom & Root mean square & F & Sig. \\
\hline Inter - Groups & 4.024 & 3 & 1.341 & 2.998 & .0349 \\
\hline Intra - Gruop & 51.898 & 116 & .447 & & \\
\hline Total & 55.922 & 119 & & & \\
\hline
\end{tabular}

Likewise, the comparison of the Tukey's ranges multiples test revealed the difference among the indicators of the sub-dimension "Human Capital" of "Intellectual Capital", highlighting the variation of the error of the variances between the indicators (Table 12).

TABLE 12. Sub-Dimension: Human Capital, ANOVA of a factor, homogeneous subsets

\begin{tabular}{|c|c|c|c|c|}
\hline Factor 4 & \multirow{2}{*}{$\mathrm{N}$} & \multicolumn{3}{|c|}{ Subset for alpha $=0.05$} \\
\cline { 3 - 5 } & & 1 & 2 & 3 \\
\hline Aptitudes & 30 & 3.20 & & \\
\hline Capacities & 30 & & 4.49 & \\
\hline Values & 30 & & & 4.93 \\
\hline Sig. & & 0.554 & 0.356 & 0.910 \\
\hline
\end{tabular}

In Table 12, results of the established comparison are presented, where the Tukey's ranges multiples test, have located three sub-sets established in the similarity and behavior difference among their averages, corresponding the first indicator "Aptitudes", with the score "Low" and an average of 3.20 points, which highlights that the informant agreed that it is necessary to enhance the cognitive skills of staff, promote changes in the rest of the people to achieve goals and assume qualities that contribute to achieving the goals of the organization.

The second subset highlights a "Moderate" average for the indicator "Capacities" of 4.49 points. In some cases, university personnel are prepared to respond to the dynamics of organizational change. Likewise, staff is encouraged to develop tasks as a team, as well as influencing people to apply their initiative in the best achievement of inter-institutional objectives. Likewise, the indicator corresponding to the Securities obtained an average of 4.93, which indicates that the development of values is propitiated as the foundation of the organization; characterizes the values of the organization focused on providing quality services. The average of the three are located in a very high category between the interval $(4.21<5.00)$.

From the foregoing, the Sub-dimension "Human Capital" had a level of significance of 0.9100 , this value being greater than $0.05,(0.9100>0.05$, level of referential significance) which shows that there are differences among the indicators compared. The above indicates that the capacities, aptitudes and variables are low, these differ significantly with respect to the averages in the sub-dimension of Human Capital to determine the components of the intellectual capital. This reflects that the university institutions have weaknesses in terms of human capital as a component of Intellectual Capital, taking into account the results for these indicators are considered high. According to the above, it is in agreement with [21] who describes Human Capital as the skills 
of employees to create tangible and intangible assets for companies through their knowledge. In addition they also emphasize that this cannot be owned by the company. In this order of ideas, it is evident that private university institutions require Human Capital, that combine skills, capacities, and values, thus the following subdimension must be taken into account to determine the theoretical guidelines for them.

\section{ii. Sub-dimension: Structural Capital}

With regard to the sub-dimension "Structural Capital", corresponding to the variable "Intellectual Capital" in the education sector, it is highlighted that when using the statistical technique for the analysis of variance (ANOVA), it was specified the significance reached by the indicators of the sub-dimension, which had a level of significance of 0.900 greater than $0.05(0.900>0.05$, being the level of referential significance). It is demonstrated that there is a highly significant difference among the compared indicators, with this it is indicated that not all have the same degree of presence within this sub-dimension, then the behavior of the subjects is shown, in the contexts investigated (Table 13).

TABLE 13. Level of significance sub-dimension: Structural Capital

\begin{tabular}{|l|l|l|l|l|l|}
\hline Source & Sum of squares & Degrees of freedom & Root mean square & F & Sig. \\
\hline Inter - Groups & .082 & 3 & .027 & .145 & .900 \\
\hline Intra - Groups & 21.850 & 116 & .188 & & \\
\hline Total & 21.932 & 119 & & & \\
\hline
\end{tabular}

The comparison of Tukey's ranges multiples test revealed the differences between the indicators of the Structural Capital sub-dimension corresponding to the variable "Intellectual Capital" as an integral part of Knowledge Management. At the same time, the variation of the errors of the variances among the indicators stands out (Table 14).

TABLE 14. Sub-dimension: structural capital, ANOVA of a factor homogeneous subsets

\begin{tabular}{|l|l|l|}
\hline Factor 5 & \multirow{N}{*}{$\mathrm{N}$} & Subset for alpha $=0.05$ \\
\cline { 3 - 3 } & & 1 \\
\hline Culture & 30 & 2.98 \\
\hline Learning & 30 & 4.11 \\
\hline Process & 30 & 4.12 \\
\hline Structure & 30 & 4.12 \\
\hline Sig. & & .911 \\
\hline
\end{tabular}

In Table 14, the results of the established comparisons are shown, in which Tukey's multiple range test located a subset, establishing a similarity of behaviors among averages, where the first, second and third indicators corresponds to "Learning", "process" and "Structure", with a score "High" respectively, and finally "Culture", with a "Moderate" score. The analysis, made it possible to observe low variation in the significant differences among the indicators. The above is the result of the opinion expressed by the population under study, through which a single group was established, revealing low significant differences between: Learning, Process, Structure and Culture.

It should be noted that the positioning of the indicator "Culture" in Table 14 is due to the preference of the respondents at the moment of issuing their answers. The above, produce as a result that the indicator "Culture" represents the first aspect that must be considered to determine the components of the Intellectual Capital that make up the private University Institutions, based on the sub-dimension "Structural Capital", reason why, it is possible to include in this Sub-dimension all the non-human intangible components of the organizations, that is, it can be considered structural capital from the culture or internal processes to the information systems or databases corresponding to the different private University institutions. On the other hand, the average of indicators located "Learning" in the category of analysis "High", $(3.41<4.20)$, where respondents said that it is promoted to develop new knowledge, encourage academic staff to share individual knowledge to transform it in social knowledge and finally to promote the personnel so that they acquire new knowledge that responds to the constant changes of the environment.

The indicator corresponding to the Process and Structure was placed in a High position $(3.41<4.20)$, which indicates that it is always stimulated so that labor relations are carried out through negotiation, as well as the existence of autonomy in the development of community projects, where a hierarchical organizational structure is applied. Regarding the structure, it is considered that the management processes generate answers to the problems, incorporate the managers in the innovative management and the mechanisms to render accounts. Finally, the Culture indicator was placed in the Moderate category whose range is $(2.61<3.40)$. These results show the same tendency in the criteria manifested by the informant subjects, who conceived that the structural 
Capital, is very high in the Private University Institutions, according to the scale used, for which sometimes the values of the organization are spread before the personal. Likewise, the strategic plans of the organization were elaborated with the help of the personnel. It is evident that organizational learning is the ability of the organization to acquire new skills and knowledge in order to respond to the dynamics of change and organizational development. Therefore, it is emphasized that teachers in the researched contexts use categories in the "High" mode, being organizational learning the ability of the organization to acquire new skills and knowledge, in order to respond to the dynamics of change and organizational development.

Likewise, the result of the indicators Process and Structure in the High category is described, being the process the set of activities that configure the directed organizational operations, either to the internal customer, to the external customer or to the suppliers. The Processes are heterogeneous depending on the activity of the company, in terms of the university institutions it is considered that the management generates answers to the problems and incorporates the managers in the innovative management and apply mechanisms to render accounts. In the same way, in the indicator "Structure", the hierarchy and the existence of autonomy in the development of community projects prevail, as well as promoting labor relations, which are carried out through negotiation. It should be noted that the private University Institutions disseminate the values of the organization to the staff, likewise, the strategic plans of the organization were elaborated with the help of the personnel and the idea that the institution serves users as a learning center for the development of knowledge was shared by the private University Institutions.

\section{iii. Sub-dimension: Structural Capital}

Regarding the study of the Relational Capital sub-dimension, it was developed on the basis of three indicators, which are evaluated in Table 15, where the behavior assumed by the respondents regarding the investigated phenomenon is exposed. It is emphasized that when using the statistical technique for the analysis of variance (ANOVA), the significance reached by the indicators of the sub-dimension was specified, which had a level of significance of 0.33 greater than $0.05(0.33<0.05$, being the level of referential significance). Based on the above, it is shown that there is a highly significant difference among the compared indicators and it is pointed out that not all have the same degree of presence within this sub-dimension.

TABLE 15. Level of Significance Sub-Dimension: Relational Capital

\begin{tabular}{|l|l|l|l|l|l|}
\hline Source & Sum of squares & Degrees of freedom & Root mean square & $\mathrm{F}$ & Sig. \\
\hline Intra - Groups & .082 & 3 & .029 & 0.145 & .033 \\
\hline Inter - Groups & 21.850 & 116 & .023 & & \\
\hline Total & 21.932 & 119 & & & \\
\hline
\end{tabular}

The comparison of the Tukey's ranges multiple test revealed the differences among the indicators of the subdimension Relational Capital corresponding to the variable Intellectual Capital as an integral part of Knowledge Management, at the same time highlighted the error variation of the variances among the indicators (Table 16).

TABLE 16. Sub-Dimension: Relational Capital, ANOVA of A Factor, Homogeneous Subsets

\begin{tabular}{|l|c|l|}
\hline \multirow{2}{*}{ Factor 6 } & $\mathrm{N}$ & Subset for alpha $=0.05$ \\
\cline { 2 - 3 } & & 1 \\
\hline Linking the Graduates & 30 & 2.41 \\
\hline Degree of Cooperation & 30 & 2.51 \\
\hline Linking with Society & 30 & 3.12 \\
\hline Sig. & & .033 \\
\hline
\end{tabular}

In Table 16, the results of the established comparisons are presented, where the Tukey's ranges multiple test have located one set, established in similarity of behaviors between average, the first indicator corresponding to the "Linking the Graduates" with the "Low" score, the second corresponds to the same set for the indicator "Degree of Cooperation" with an average of 2.51. Likewise, the indicator "Linking with Society" obtained a "Moderated" score. The average of indicators located the "Linking of Graduates" in the category of analysis "Low", $(1.81<2.60)$, where respondents said that almost never monitoring the graduates to detect the needs of them. In the same way the graduates are uninformed and there are no university activities to meet the demands of the productive sector.

Regarding the indicator "Degree of Cooperation", it was placed in the "Low" category $(1.81<2.60)$, where respondents stated that knowledge generated in professional practices is almost never managed and socialized. Finally, the indicator corresponding to "Linking with Society" was placed in the "Moderate" category (2.61 $<3.40$ ) according to the results of the informants in the surveys conducted, where they stated that they sometimes consider establishing agreements with the productive sector, governmental entities and professional 
associations, for the assignment of interns' vacancies.. The above refers to the relational capital, which is based on the existing relationship among the partners of the organization and helps in the generation of strategies that allow to obtain competitive advantages [22]. This reflects the value that all external relationships have for the company.

This type of capital includes the value generated by the company's relationships, not only with customers, suppliers and shareholders, but also with its stakeholders, both internal and external. Therefore, the linking with the graduates is a way of relating the Universities with society and how they are inserted in the socioeconomic context. Therefore, the productive apparatus becomes a factor of linkage with the different sectors that make life in a society. In this sense, universities play a fundamental role by involving their graduates in the various teaching, research and extension activities.

In today's society, companies and organizations are progressing thanks to the dissemination, application and systematization of the knowledge created or obtained. One of the learning processes of organizations occurs through the inter-institutional relationships, which persist in order to form innovative and competitive communities. From the above, it follows that the importance of relational capital lies in the connections that conform with the environment and how knowledge becomes a differentiator in these organizations.

\section{IV.CONCLUSION}

The conclusions of the study are presented to propose theoretical guidelines on knowledge management as a platform in the strengthening of intellectual capital in private universities, In characterizing the stages of knowledge, the need was evident strengthening knowledge phases creation, capture and acquisition, development and dissemination, through implementation of strategies and policies aimed at managing knowledge in teachers and interns. Regarding the identification of knowledge transfer mechanisms of private universities, it was found necessary to promote and strengthen alliances, agreements with sectors of society to facilitate the fluency and knowledge transfer of interns to the productive sectors and vice versa, in order to optimize the knowledge that is generated within higher education institutions.

On the other hand, there is evidence of a weak technological structure that limits the promotion and strengthening of internal telematics networks (teachers and students) and external networks (public and private organizations) that influence transfer of knowledge considered a key element of competitiveness and innovation in the society. Likewise, to determine the components of intellectual capital using the Intellectus model in private universities, it was valued in a low category and where it is observed that in the internship areas of the engineering faculties there are few initiatives and actions tending to strengthen work in multidisciplinary teams that allow a greater flow and exchange of knowledge. Another aspect to mention is the need to promote followup programs for graduates, which makes it possible to assess the relevance of educational programs as a primary element of the curriculum, to integrate them into the labor market that demands more integral and competitive professionals.

\section{REFERENCES}

[1] H. Harlow, “The effect of tacit knowledge on firm performance,” Journal of Knowledge Management, vol. 12, issue 1, pp. 262-271, 2008.

[2] K. M. Wiig, R. de Hoog and R. Van Der Spek, "Supporting knowledge management: A selection of methods and techniques," Expert System with Applications, vol. 13, issue 1, pp. 15-27, 1997.

[3] M. Festing and L. Shäfer, "Generational challenges to talent management: A framework for talent retention based on the psychological-contract perspective,” Journal of World Business, vol. 49, issue 2, pp. 262-271, 2014.

[4] G. Von Krogh, "How does social software change knowledge management? Toward a strategic research agenda," The Journal of Strategic Information Systems, vol. 21, issue 2, pp. 154-164, 2012.

[5] S. Sunalai and M. Beyerlein, "Exploring knowledge management in higher education institutions: processes, influences, and outcomes,” Academy of Educational Leadership Journal, vol. 19, issue 3, pp. 289-308, 2015.

[6] I. Nonaka, “The Knowledge-Creating Company,” Harvard Business Review, (Best of HBR), pp. 164-168, 2007.

[7] K. H. Leitner, "Intellectual capital reporting for universities: conceptual background and applications for Austrian universities," Research evaluations, vol. 13, issue 2, pp. 129-140, 2004.

[8] T. Oktavia, H. Hendric and S. Adi, "Integration Model of Knowledge Management and Social Media for Higher Education," Telkomnika, vol. 15, issue 2, pp. 678-688, 2017.

[9] K. Deejring, "The design of Knowledge management to develop creative thinking for higher education with project base learning," Proceedings of the 6th Multidisciplinary Academic Conference 2016. Academic Conferences Associations, pp. 63-70, 2016.

[10] L. Trivella and N. Dimitrios, "Knowledge Management Strategy within the Higher Education. The Case of Greece," Procedia - Social and Behavioral Sciences, vol. 175, pp. 488-495, 2015.

[11] S. Abu Naser, M. Al shobaki and Y. Abu Amuna, "Knowledge Management Maturity in Universities and its Impact on Performance Excellence "Comparative study",” Journal of Scientific and Engineering Research, vol. 3, issue 4, pp. 4-14, 2016.

[12] Y. Yilmaz, "Knowledge management in e-learning practices," The Turkish Online Journal of Educational Technology, vol. 11, issue 2, pp. 150-155, 2012.

[13] P. Leavy, Research design: Quantitative, qualitative, Arts-based and community-based participatory research approaches. New York: The Guilford press, 2017

[14] L. Christensen, R. Burke and L. Turner, Research Methods, Design, and Analysis. Harlow, England: Pearson Education Limited, 2014.

[15] M. N. Dudin and E. Frolova, "The Balanced Scorecard as a Basis for Strategic Company Management in the Context of the World Economy Transformation,” Asian Social Science, vol. 1, issue 3, pp. 282-288, 2015. 
[16] M. Birasnav, "Knowledge management and organizational performance in the service industry: The role of transformational leadership beyond the effects of transactional leadership”, Journal of Business Research, vol. 67, issue 8, pp. 1622-1629, 2014.

[17] O. Sorenson and L. Fleming, "Science and the diffusion of knowledge," Research Policy, vol. 33, issue 10, pp. 1615-1634, 2004.

[18] F. Huber, "Knowledge-sourcing of R\&D workers in different job positions: Contextualizing external personal knowledge networks," Research Policy, vol. 42, pp. 167-179, 2013.

[19] A. Kianto, P. Ritala, J. C. and M. Vanhala, "The interaction of intellectual capital assets and knowledge management practices in organizational value creation. Journal of Intellectual Capital,” vol. 15, issue 3, pp. 362-375, 2014.

[20] E. Bueno, Modelo Intellectus: Medición y Gestión del Capital Intelectual (Documentos Intellectus $\mathrm{N}^{\circ}$ 5). Madrid: IADE. Universidad Autónoma de Madrid, 2002.

[21] R. Hejazi, M. Ghanbari and M. Alipour, "Intellectual, Human and Structural Capital Effects on Firm Performance as Measured by Tobin's,” Q. Knowledge and Process Management, vol. 23, issue 4, pp. 259-273, 2016.

[22] C. H. Wang, "How relational capital mediates the effect of corporate reputation on competitive advantage: Evidence from Taiwan high-tech industry,” Technological Forecasting and Social Change, vol. 82, pp. 167-176, 2014.

\section{AUTHOR PROFILE}

Liriam Estrada works at Rafael Belloso Chacín University. Mrs. Estrada completed his doctorate from Rafael Belloso Chacin University (Venezuela).

Raul J. Martelo works as full-time professor at the University of Cartagena (Colombia). Mr. Martelo completed his magister from Industrial University of Santander (Colombia). Mr. Martelo completed his undergraduate in Systems Engineering at the Industrial University of Santander.

Piedad M. Montero works as full-time professor in the University of Cartagena (Colombia). Mrs. Montero completed his doctorate from Rafael Belloso Chacin University (Venezuela). Mrs. Montero completed his undergraduate in Food Engineering at the University of Cartagena. 